\title{
Feed-back on the development of a small scale Contact Erosion Test in the laboratory (characteristic size $\sim 30 \mathrm{~cm}$ )
}

\author{
R. Beguin, P. Pinettes \\ geophyConsult, Chambéry, France \\ C. Picault \& L. Duchesne \\ CACOH, CNR, Lyon, France
}

J.-R. Courivaud

Centre Ingénierie Hydraulique -EDF, Le Bourget du Lac, France

ABSTRACT: To determine the hydraulic load requested to initiate contact erosion process, tests are per-
formed with an apparatus called the "Contact Erosion Test". This device originally results from research car-
ried out by Grenoble University, Électricité de France and Compagnie Nationale du Rhône, at the scale of $\sim 60$
$\mathrm{~cm}$. It has been adapted to a smaller scale in geophyConsult laboratory to conduct tests on samples extracted
from core drilling. The instrumentation was improved to enable a better control of the hydraulic loading and
avoid biases. The test protocol was modified, especially to better constrain the soil density at the interface.
From the first series of test, we drew conclusions on the test repeatability and on the influence of parameters
of the soil state. Discrepancies with previous results obtained at the scale of $\sim 60 \mathrm{~cm}$ were identified. There-
fore, a new erosion test campaign was planned to confirm and determine the reasons for these differences.

\section{INTRODUCTION}

Contact erosion is a type of internal erosion which develops in earthen embankments at the contact between a layer of fine soil (clay, silt or sand) and a layer of coarse soil (coarse sand, gravel...) when subject to a tangential flow. Particles of the fine layer are detached at the interface and transported through the coarse soil layer.

Different configurations of the process exist depending on the orientation of the layers and the flow compared to gravity (Figure 1). The most studied configuration in the literature is the case of a horizontal gravelly layer above a sandy layer, with a flow tangent to this interface (de Graauw, 1983, Brauns, 1985, Bezuijen, 1987, Wörman 1992). This configuration is common in embankments with sandy cores protected by gravelly shells, subject to overtopping through the shell for example. The theoretical and experimental studies carried out show that sand particles are detached at the interface and transported through the coarse layer with a process similar to riverbed erosion. However, the hydraulic loading on the sand particles is influenced by the presence of the coarse layer, and equations for riverbed erosion need to be adapted in order to model this phenomenon (Bezuijen, 1987, Wörman 1992, Den Adel 1994). Scour zones are created by erosion in the sandy layer and the gravel particles progressively fall, generating settlement that propagate towards the surface. This erosion process progress if 1) no geometrical filtration occurs between the transported sand particles and the gravel layer, 2) the hy- draulic loading remains sufficient to detach and transport the particles.

The configuration of a horizontal fine soil layer above coarse soil layer has been much less studied (Schmitz, 2007, Guidoux, 2010) however it is a situation often found in fluvial dykes (Rhone and Rhine rivers for example). These structures are usually made of silty or clayey cores constructed above a gravelly foundation and submitted to horizontal seepages. The main difference with the previous configuration is the direction of gravity: the detachment of particles from the fine soil is facilitated due to the fact that gravity is now a destabilizing force. Moreover, particles of the coarse layer (gravel...) do not fall into the scour zones of the fine layer.

The consequences of this erosion process are very different depending on the configuration considered. In the configuration of a coarse layer above a fine layer, the erosion of the fine soil leads to progressive settlement that propagate to the coarse layer (Figure 2 ). For typical flow velocities, it is a rather slow process. On the contrary, in the case of a fine soil layer above a coarse soil layer, it has been shown that, in specific situations, contact erosion can lead to the formation of an open pipe through the fine layer which, if not stopped by other part of the structure, can conduct to a rapid failure of the structure $(\mathrm{Be}-$ guin, 2011, Beguin 2012).

This observation brought Electricité De France and Compagnie Nationale du Rhône to initiate a research program dedicated to the study of this process, from the sample scale to the structure scale 
(Beguin, 2011). The main results of this research are summarized in the first part of this paper, focusing on the coherence obtained between the processes observed at different scales. Second, a new contact erosion apparatus developed in order to industrialize the contact erosion test at laboratory scale is presented, and the first experimental results detailed. Finally the discrepancies with previous studies are underlined and proposed explanations are discussed.
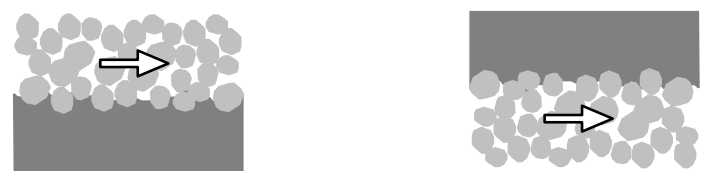

Figure 1. Diagram of configurations for contact erosion : two horizontal soil layers, with tangent flow and either a coarse soil above fine soil (left), or fine soil above coarse soil (right).
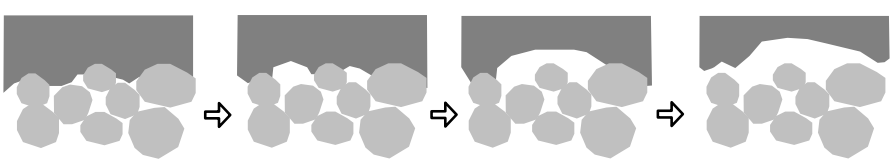

a)

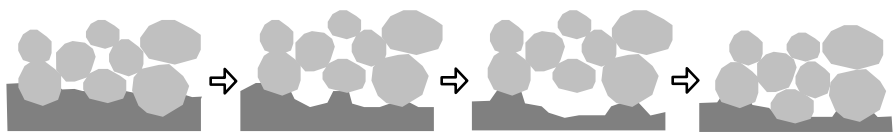

b)

Figure 2. Contact erosion progression in configuration : a) fine soil above coarse soil b) coarse soil above fine soil.

\section{CONTACT EROSION RESEARCH PROGRAM MAIN RESULTS}

\subsection{Sample scale tests $(70 \times 30 \times 25 \mathrm{~cm})$ at Grenoble University.}

First, tests were conducted at the sample scale, in the laboratory LTHE (University of Grenoble, France, Guidoux, 2010; Béguin, 2011). In a rectangular cell $(70 \times 30 \times 25 \mathrm{~cm})$ a coarse soil layer and a fine soil layer were set-up successively, and saturated with water. During the test, the coarse layer was subjected to a controlled flow. The hydraulic loading was increased in successive steps, 30 min long, with constant flow-rate. When the coarse soil was above the fine soil, peaks of turbidity were observed at each change in the hydraulic loading and can be explained by an erosion of the weakest fine soil particles in the zones of highest flow velocity. As the flow went through the coarse layer, it was spatially variable, due to the arrangement of the pores. This phenomenological explanation of turbidity peaks was consolidated by a characterization of the flow variability and a statistical modeling of the erosion process (Beguin, 2013). From a specific flow velocity in the coarse layer, finite turbidity remained at the end of the step, and it was considered for these experiments that this velocity corresponds to a "critical" velocity for contact erosion (Guidoux, 2010). Other criteria for critical velocity have been used in the literature such as visual observation, specific transport rate, linear extrapolation of the transport rate towards zero,... underlining the complexity of the concept of threshold in erosion processes. The model proposed (Beguin, 2013) shows that erosion rate evolves with time: the weakest soil particles are quickly eroded leaving stable particles on the interface, which need higher hydraulic loading to be eroded. Therefore, the erosion progress by gradual scour of the fine layer, causing i) a collapse of the coarse particles in the scour holes which prevent the apparition of open cavities, ii) a segregation at the interface, with an accumulation of the coarsest particles of the fine soil layer. Regardless the criterion for erosion initiation chosen, critical Darcy velocities obtained in this configuration lay between 1 and $10 \mathrm{~cm} / \mathrm{s}$ for sandy or silty soil but can be higher for clayey soil are coarser soils. These values are well estimated by relation derived from criteria of riverbed erosion, taking into account the specificity of the eroding flow (Bezuijen, 1987, Beguin, 2011) (Figure 3).

During this study we focused on the case of the fine soil above the coarse soil. In this configuration, turbidity peaks at each change of hydraulic loading were also observed, but a second phenomenon occurred. The erosion at the interface generated holes in the fine layer which can collapse, producing progressive settlements in the fine soil layer in a mechanism similar to what was observed when the coarse soil was above the fine soil. However, if the soil is sufficiently cohesive, the holes can remain open. This cavity formation initiates an instable process: erosion enlarges the cavity which concentrates a larger part of the flow, which increases the erosion rate. As this process propagates, an open pipe appears in the fine layer and influences the global permeability of the sample. This phenomenon is detected during the tests by different ways: i) increase of turbidity of the effluent which is not directly related to a change of hydraulic loading, ii) decrease of the global hydraulic gradient due to the pipe formation, iii) increase of the global hydraulic gradient due to the clogging of the coarse layer linked with the high erosion and transport rate, iv) settlements of the top surface of the sample. Contact erosion tests using this configuration are scarce in the literature. Results obtained by LTHE laboratory have shown that velocities for pipe initiation are of the same order of magnitude than results in the case of a coarse soil above a fine soil (Figure 3). 


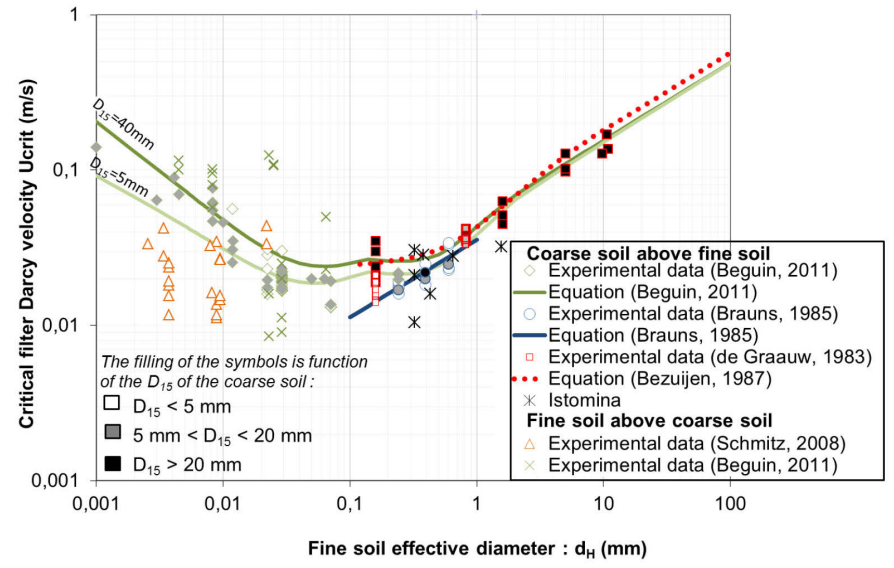

Figure 3.Critical velocity for contact erosion initiation obtained in the literature and during the research program.

\subsection{Structure scale tests $(800 \times 400 \times 200 \mathrm{~cm})$ at CNR laboratory.}

Contact erosion tests have been performed at a larger scale, in Compagnie National du Rhône laboratory from 2010 to 2012. Tests were performed in a concrete box $8 \mathrm{~m}$ long, $2 \mathrm{~m}$ high and $4 \mathrm{~m}$ width (Figure 4 and 5). First, a $20 \mathrm{~cm}$ gravel layer was set-up at the bottom and, second, a $2 \mathrm{~m}$ thick fine soil layer was compacted in successive $20 \mathrm{~cm}$ layers. A constant hydraulic head was applied at the entry of the coarse layer and increased by successive steps $24 \mathrm{~h}$ long. Similar phenomena as observed at sample scale occurred: peaks of turbidity were noticed at each change of hydraulic loading, cavities formed at the interface and these generated settlements which progressively reached the top of the sample and, in some cases, an unstable process initiated and lead to a pipe formation through the whole structure. These phenomenological observations at a large scale were therefore consistent with results at the small scale. Moreover, Darcy velocities in the coarse layer for pipe formation agreed with results at the smaller scale despite the fact that the durations and protocols of the tests were significantly different.

These results imply that tests at sample scale in the laboratory could be efficient to predict the behavior at the structure scale. Therefore, the research program continued with the idea to developed the sample scale apparatus in order to give to engineer a robust tool to characterize the resistance against contact erosion of real embankment.

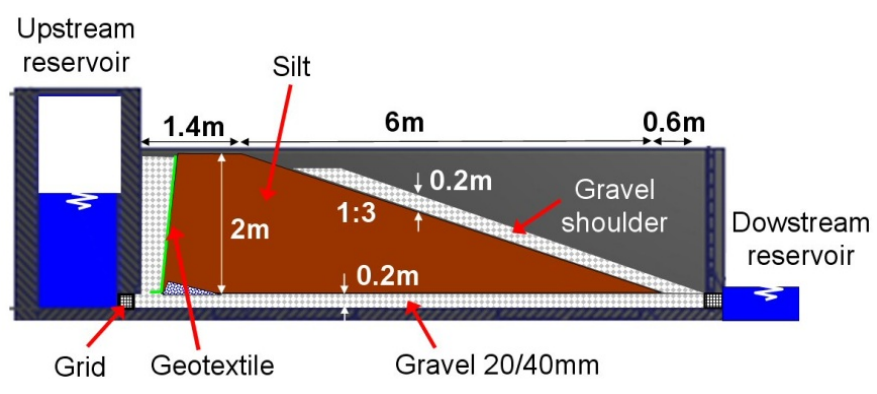

Figure 4. Diagram of large-scale test conducted at Compagnie National du Rhône laboratory.

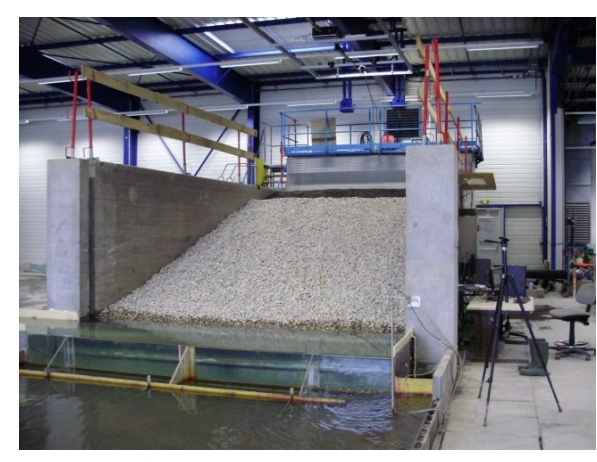

Figure 5. Photo of large-scale test conducted at Compagnie National du Rhône laboratory.

\section{THE NEW CONTACT EROSION TEST}

\subsection{The apparatus}

In 2014-2015, a new apparatus was set-up in geophyConsult laboratory with the support of Electricite de France and Compagnie Nationale du Rhone. The objective was to industrialize the device to be able to characterize at a reasonable cost the resistance against contact erosion of soil samples collected on site. In most cases, the samples are taken from drilling which leads to a severe constraint for erosion test: the available soil quantities for the test are limited by the volume of the drilling in the fine and coarse layers that need to be tested. Therefore, a new cell was constructed with a limited volume for the soil sample: 30x20x20 cm (Figure 6 and 7).

In order to be able to detect any side effect on the test, the cell was entirely made of Perspex. A constant flow-rate is imposed in the coarse layer and monitored by a flow-rate meter. The pressure drop in the sample is recorded by a differential pressure transducer. The quantity of eroded soil is evaluated by two ways : i) fine particles in suspension are quantified by turbidity measurement, ii) coarse particles transport by bed-load are collected in a recipient at the exit of the cell. A rubber bag is used to apply an overload between 10 and $200 \mathrm{kPa}$ on the soil sample. This bag is filled by water underpressure via a graduated column in order to monitor the volume changes of the rubber bag during the test. These vol- 
ume changes are linked with the settlement of the top surface of the sample.

Compared to previous apparatus, the range of flow that can be applied was improved by using a pressurized reservoir instead of gravity flow. An entry pressure of 1 bar can be obtained which corresponds to a hydraulic gradient in the cell of around $25 \mathrm{~m} / \mathrm{m}$. The regulation of the flow was also improved by replacing the manual valve previously used by an automatic valve, controlled by a PID controller. Thanks to this system, either constant head, constant flow-rate or linearly increasing hydraulic loading can be programed.

The volume of water needed for one test has been decreased by using a recirculation system: when the turbidity of the effluent is below 4 NTU, water is redirected to the entry reservoir. When erosion starts to be intense and the sediment load in the exit flow increases, a valve automatically switches and exit flow is evacuated. This system saves water and enables a longer test.

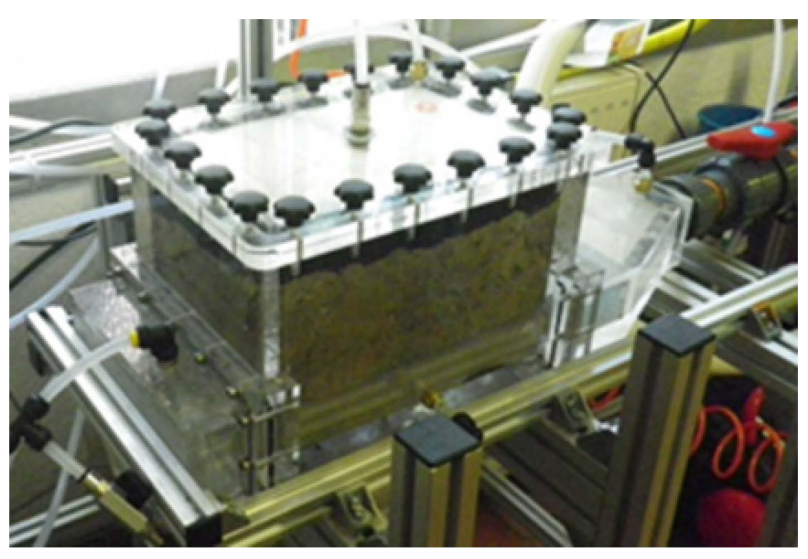

Figure 6. Photo of the new cell during a CET test.

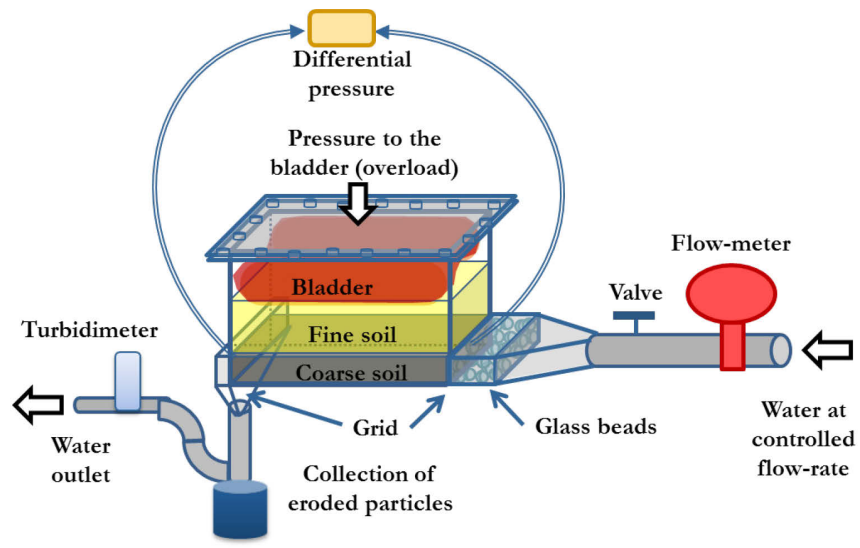

Figure 7. Diagram of new contact erosion apparatus.

\subsection{Protocol}

The coarse soil sample is dried, sieved to remove the particles above $20 \mathrm{~mm}$. The fine soil is dried, sieved to remove the particles above $4.75 \mathrm{~mm}$ and moistened to the chosen water content. It is stored in a tight bag for a minimum of $24 \mathrm{~h}$ to let the water content homogenize. In specific cases, the fine soil can be tested at its natural water content avoiding the drying and wetting phases.

First, the coarse soil is set-up in the cell, using bubble wrap stuck on the internal side of the cell as roughness to avoid side effects. Usually, the coarse soil is manual compacted dry until no settlement is observed ( $\sim$ minimum void ratio). Second, the fine soil is set-up by manual compaction of successive layers $2 \mathrm{~cm}$ thick. The needed quantity of soil for the volume of one layer at the target density is prepared and compacted until the measured thickness reach $2 \mathrm{~cm}$.

A preliminary test is performed in a Proctor mold to evaluate the quantity of fine soil which falls into the coarse layer. It consists in i) compacting a $2 \mathrm{~cm}$ layer of fine soil in the Proctor mold at the given density and record the number of blows needed, ii) set-up a gravel layer at the minimum void ratio which fills entirely the main part of the Proctor mold, iii) set-up a fine soil layer in the detachable collar using the same number of blows, iv) screed the fine soil layer, v) calculate the amount of fine soil fell in the coarse soil by making the difference between the final weight of the mold (filled by the coarse layer and the fine soil percolated) and the initial mold (filled by the coarse layer). From this result, the amount of soil needed for the first layer of fine soil in the contact erosion test can be calculated, making the hypothesis than the percentage that will fall in the coarse layer is identical to the percentage obtained with the preliminary test in the Proctor mold.

When 3 layers of fine soil have been set-up, the rubber bladder is set-up and the cell is closed. Saturation of the sample is performed by first filling the cell with $\mathrm{CO}_{2}$ and then filling it by desaerated water. This protocol avoids the apparition of air bubbles at the interface between the two layers. The sample is left in place for a minimum of $12 \mathrm{~h}$. The test is then performed by applying increasing $30 \mathrm{~min}$ constant flow-rate steps. Changes of flow-rate are performed by a linear increase at constant rhythm $(+0,001 \mathrm{l} / \mathrm{s}$ per second).

The dismantling procedure has also been modified in order to be able to recover blocks of fine soil after the end of the test and turn them back, to observe the state of the interface, and detect the pipes (Figure 8).

\subsection{First results}

Repeatability tests have been performed in order to validate the new apparatus. Rounded gravel $12 / 20 \mathrm{~mm}$ has been used as the coarse soil layer and silt from Bourg-Lès-Valence along the Rhone River for the fine soil (Figure 9). The silt has been madeup at $1.52 \mathrm{~g} / \mathrm{cm}^{3}$ of dry density and $18 \%$ of water 
content. Five constant flow-rate steps were performed: $0.5-2-5-8-12 \mathrm{~cm} / \mathrm{s}$.

A typical result for these tests is shown on Figure 10 . The velocity in the coarse layer was increased by successive $30 \mathrm{~min}$ steps. Turbidity was monitored as an indicator of erosion: peaks were observed at each changes of hydraulic loading but as detailed before (cf. \$2) they can be explained by a wash out of the coarse layer and the interface. Overall, the maximum intensity of these peaks decreased during the test. During step 6, at $186 \mathrm{~min}$, a sudden increase of turbidity is observed which is not linked with a change of the hydraulic loading. Simultaneously, the hydraulic gradient starts to decrease. These observations are consistent with the progression of contact erosion, and the formation of a pipe: a large quantity of soil is eroded and transported and the opening of a cavity creates an easy path for the flow, which decreases the global hydraulic gradient. This step is considered as the first step with pipe formation.

During the repeatability campaign, three different cases were observed : 1) pipe formation during the step at $8 \mathrm{~cm} / \mathrm{s}, 2$ ) at $12 \mathrm{~cm} / \mathrm{s}$ or 3 ) no erosion during step at $12 \mathrm{~cm} / \mathrm{s}$ which is the maximum velocity that can be applied. The Darcy velocity for the last step without progression of contact erosion and the velocity for the first step with erosion progression are plotted on the Figure 11. The minimum velocity for erosion progression is between these two values, and tests with smaller increments between steps are necessary to refine it. However, these results give an idea of the variability that can expect: depending on the test, erosion starts at steps with velocity between 8 and $12 \mathrm{~cm} / \mathrm{s}$.

A rough sensitivity analysis has been performed by modifying the dry density (Figure 12) and the water content (Figure 13) of the fine soil keeping all the other parameters identical. Three tests with very low dry density $\left(1.09\right.$ and $\left.1.26 \mathrm{~g} / \mathrm{cm}^{3}\right)$ lead to velocity for pipe formation significantly smaller than the velocity obtained during repeatability tests. However, other tests need to be carried out with intermediate density (between $1.26 \mathrm{~g} / \mathrm{cm}^{3}$ and $1.52 \mathrm{~g} / \mathrm{cm}^{3}$ ) and a higher density to well understand the influence of this parameter. Two tests with higher water content and one test with smaller water content lead to velocity for erosion not significantly different than the results of the repeatability tests.

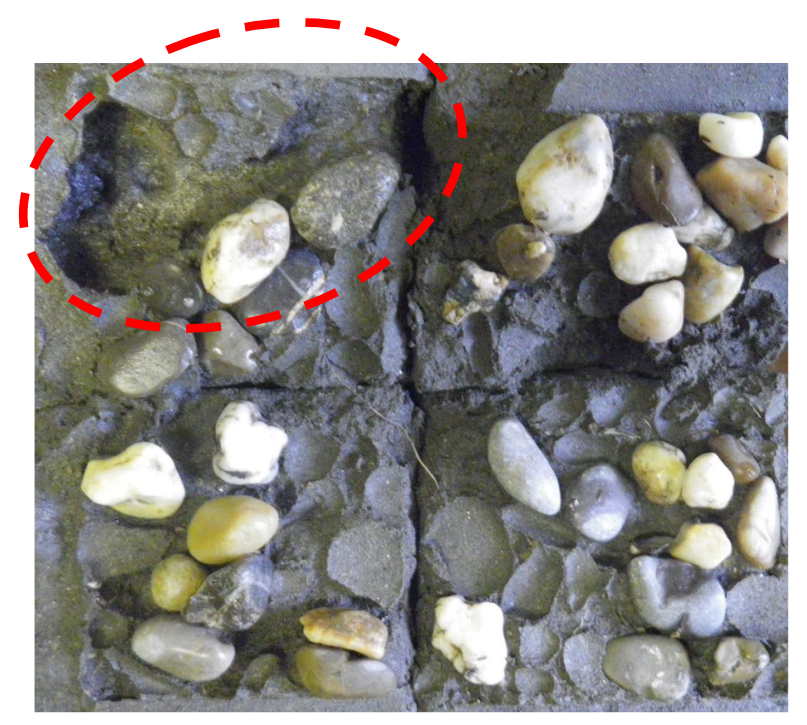

Figure 8. Interface between coarse soil and fine soil seen from below after the end of the test. The fine soil layer has been cut in four parts in order to be able to turn it back. Part of the gravel from the coarse soil has been removed and part of them is still in place. The pipe created by erosion is underline by a red circle

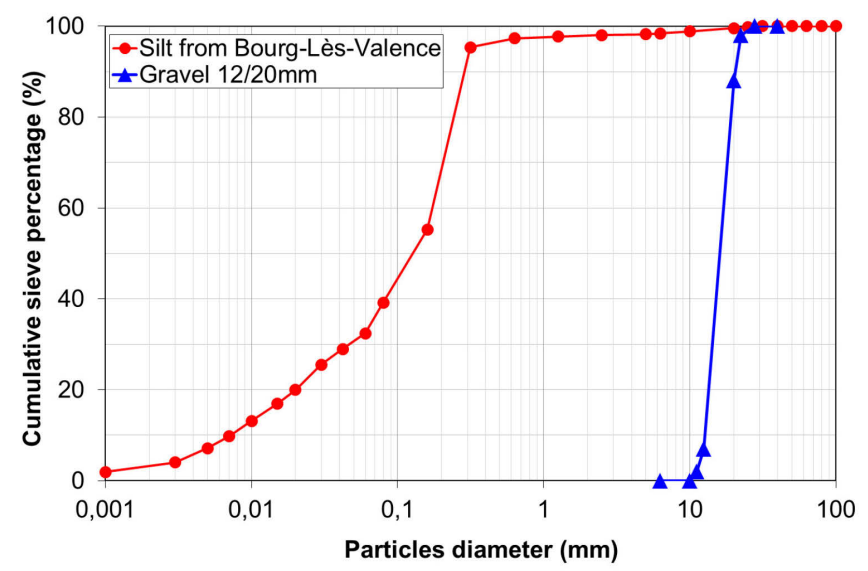

Figure 9. Grading curves for Bourg-Lès-Valence silt and $12 / 20 \mathrm{~mm}$ gravel.

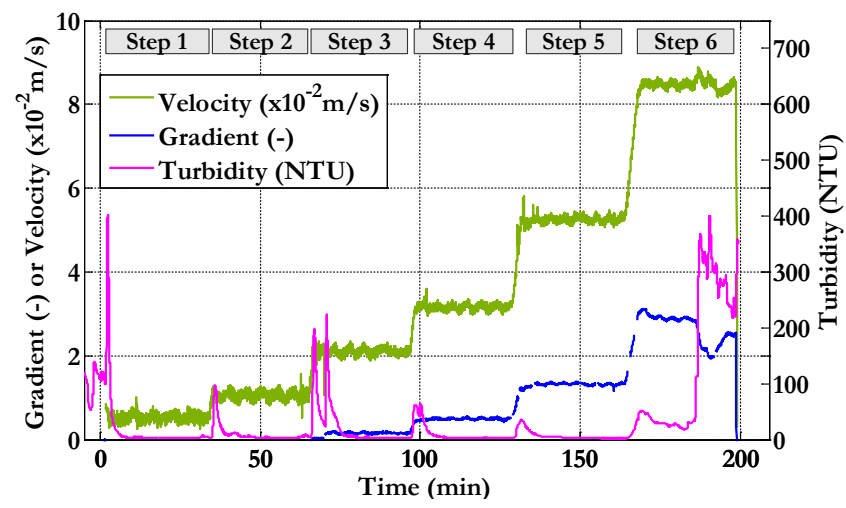

Figure 10. Classical result of a Contact Erosion repeatability tests. 


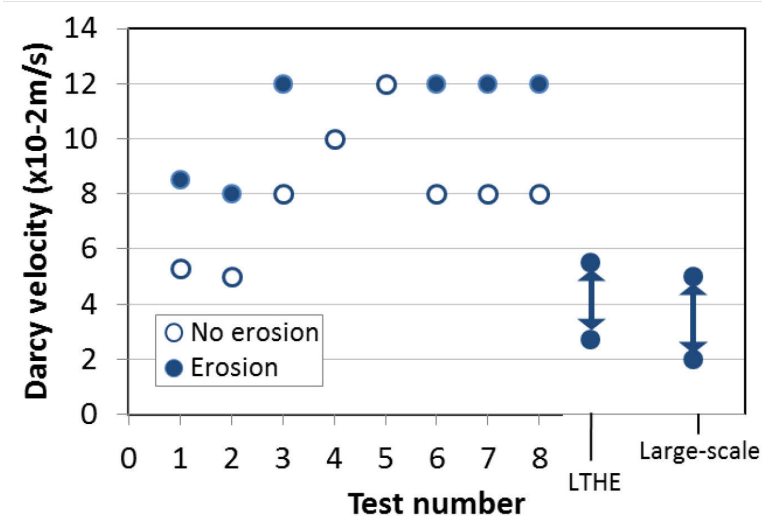

Figure 11. Repeatability test of contact erosion with Bourg-LèsValence silt and 12/20 mm gravel.

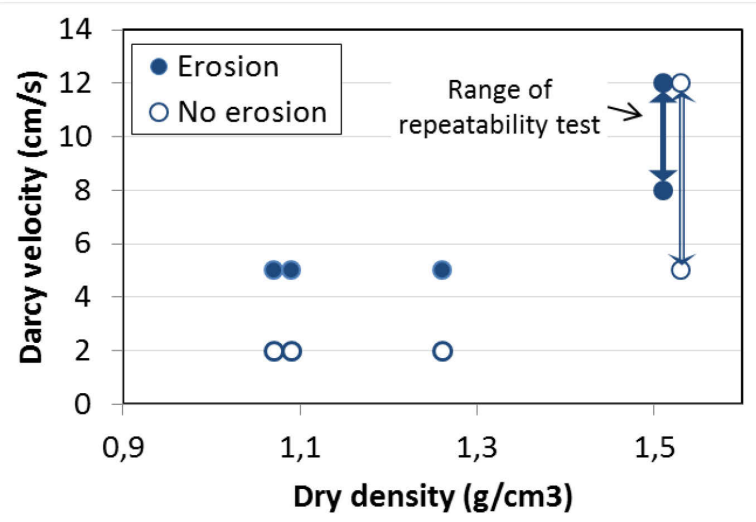

Figure 12. Influence of dry density on the results.

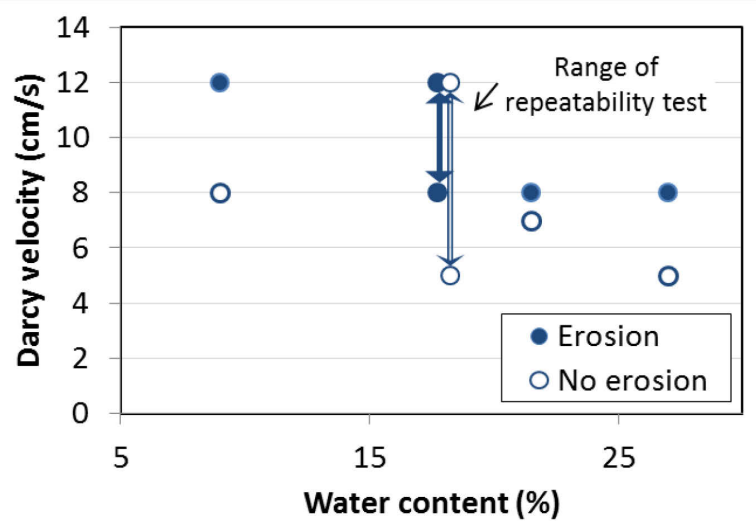

Figure 13. Influence of water content on the results.

\section{DISCREPANCY BETWEEN RESULTS AT DIFERENT SCALES}

The range of velocity for erosion progression obtained during tests at sample scale at Grenoble University and structure scale in CNR laboratory are plotted in Figure 11. As it can be seen, there is an agreement between both results and no significant difference can be noticed despite the fact that spatial scale, time duration and protocol were different.
However, there is clear discrepancy with the results from the new apparatus. Several explanations were considered. Whilethe fine soil samples came from the same stockpile for both experiments, there were four years between both erosion campaign and the stockpile is huge (thousands of cubic meters). It is therefore possible that the fine soil tested in both tests is not exactly the same. Second, the test protocol evolved: dry density is better a constraint in the new apparatus, water supply is now coming from a pressurized reservoir with automatic regulation and overload is adjusted during the test to maintain constant effective stress. Finally, the new cell is smaller $(30 \times 20 \times 20 \mathrm{~cm})$ than previous cell $(70 \times 30 \times 25 \mathrm{~cm})$. The size of the new tests was chosen with the objective to enable tests on samples from drilling for which the soil quantity available are sometimes scarce but maintaining a a priori sufficient number of coarse particles in contact with the fine soil at the interface. In the new apparatus, using gravel $10 / 20 \mathrm{~mm}$ as coarse layer, there are around 200 particles in the interface against $\sim 700$ in Grenoble University cell and $\sim 10^{5}$ in large scale tests.

To choose between these explanations, a new common contact erosion test campaign is planned in Grenoble University and geophyConsult, using fine and coarse soils from a homogenized stock and identic test protocol. If discrepancies remain, it will demonstrate that there is significant scale effect in this test and that the $30 \times 20 \times 20 \mathrm{~cm}$ cell is too small to obtain relevant results. Tests on samples from drilling will therefore be restraint to the cases when enough soil is available, because the diameter of the drilling is large, or because the thickness of homogeneous soil in the tested layer is sufficient.

\section{CONCLUSION \& PERSPECTIVES}

A new apparatus was set-up in the geophyConsult laboratory with the support of Electricite de France and Compagnie Nationale du Rhone in order to perform contact erosion test on samples from drilling. The size of the new cell is smaller $(30 \times 20 \times 20 \mathrm{~cm})$ than the previous device used in Grenoble University $(70 \times 30 \times 25 \mathrm{~cm})$. Preliminary results show that phenomena observed are similar as observed in previous research campaign: at a specific hydraulic loading, contact erosion initiates pipe formation in the fine soil layer which lead to high erosion rates. Repeatability tests were conducted on the same fine soil/coarse soil couple and lead to a first estimate of the range of variation of the results that can be expected : for this couple, erosion progression starts between 8 and $12 \mathrm{~cm} / \mathrm{s}$ of Darcy velocity in the coarse soil. A rough sensitivity analysis was performed on dry density and water content. A positive influence of the density on the velocity for erosion was identified. These parametric studies will be re- 
fined and confirmed by performing other tests with smaller increment of hydraulic loading between the steps.

A discrepancy between these flow velocities and previous results either at sample scale at Grenoble University and at structure scale at Compagnie Nationale du Rhône has been highlighted. These discrepancies are easy to explain due to numerous differences in the experiments, discrepancies with sample scale are challenging. Different explanations were proposed and a new common erosion test campaign is planned to determine if the size of the new cell is responsible of this gap or if other parameters of the protocol can explain it.

Development of the apparatus is planned to be continued in order to offer the market a robust tool for engineers.

\section{REFERENCES}

Beguin R., Philippe P., Faure Y.-H. 2013 Pore-scale flow measurements at the interface between a sandy layer and a model porous medium: Application to statistical modeling of contact erosion, Journal of Hydraulic Engineering, 139(1), 1-11.

Beguin, R., Fry, J. J., Picault, C., Courivaud, J. R., Faure, Y. H., Philippe, P. (2012). Control of the risk of dike failure caused by contact erosion. In: Proceedings of 6th International Conference on Scour and Erosion, Paris, pp. $1551-1558$

Beguin R. (2011), Etude multi-échelle de l'érosion de contact au sein des ouvrages hydrauliques en terre, $\mathrm{PhD}$, Université de Grenoble.

Bezuijen A., Klein-Breteller M., Bakker K.J. (1987), Design criteria for placed block revetments and granular filters, Proceedings of the 2nd international conference on coastal \& port engineering in developing countries, Beijing, China.

Brauns J. (1985) Erosionsverhalten geschichteten Bodens bei horizontaler Durchstromung, Wasserwirtschaft, vol 75, p. 448-453.

De Graauw A., Van der Meulen T., Van Der Does De Bye M. (1983), Design criteria for granular filters, publication no. 287, Delft Hydraulics Laboratory, Emmerloord.

Den Adel H., Koenders M.A , Bakker K.J. (1994), The analysis of relaxed criteria for erosion-control filters, Canadian $\mathrm{Ge}$ otechnival Journal, vol 31(6), p. 829-840.

Guidoux C., Faure Y.-H., Beguin R., Ho C.-C (2010), Contact erosion at the interface between granular filter and various base-soils with tangential flow, Journal of Geotechnical and Geoenvironmental Engineering, vol 136(5), p. 655775.

Wörman A., Olafsdottir, R. (1992) Erosion in a granular medium interface, J. Hydraul. Res.,vol 30(5),p. 639-655.

Schmitz S. (2007), Zur hydraulischen Kontakterosion bei bindigen Basiserdstoffen, PhD thesis, Universität der Bundeswehr, Munich, Germany, 2007. 